\title{
Ebenaceae Vent. do Estado do Rio de Janeiro*
}

\author{
Rosana Conrado Lopes ${ }^{1}$
}

\begin{abstract}
RESUMO
O presente trabalho trata do estudo taxonômico das espécies de Diospyros Dalech. ex L., pertencente a família Ebenaceae, ocorrentes no Estado do Rio de Janeiro. Estas espécies são aqui redescritas, ilustradas e ordenadas em chave analítica que facilita sua identificação. É feito um estudo comparativo dos padrões de nervação das folhas, dos tipos de inflorescências e da morfologia dos frutos. É apresentada uma tabela de épocas de floração e frutificação, além de informações referentes ao habitat, nome vulgar e utilidade de cada espécie, bem como uma lista dos nomes dos coletores e mapas de distribuição geográfica.
\end{abstract}

Palavras-chave: Ebenaceae, Diospyros, Rio de Janeiro.

The present work consist of a taxonomic study of species of Diospyros Dalech. ex L. belong of the Ebenaceae family that occur in the state of Rio de Janeiro. These species are here redescribed and illustrated, and ordered in an analytic key, making their identification easier. A comparative study of leaves veineing patterns, kinds of inflorescence and fruit morphology was made. The work include a table of floration and frutification time, besides information concerning their habitat, common name, utility, collector's names and geographical distribution maps.

Keywords: Ebenaceae, Diospyros, Rio de Janeiro.

\section{INTRODUÇÃO}

A ordem Ebenales consta de cinco famílias: Ebenaceae, Sapotaceae, Styracaceae, Symplocaceae e Lissocarpaceae, distribuídas principalmente, nos trópicos, e todas com representantes na flora do Brasil (Cronquist 1981).

A família Ebenaceae Vent. possui cerca de 450 espécies subordinadas a 5 gêneros. Diospyros tem ampla distribuição nas regiões tropicais e subtropicais, enquanto Euclea, Rhaphidanthe e Royena, são provenientes da África e Tetraclis endêmica de Madagascar (Cronquist 1981).

O gênero numericamente mais significativo da família é Diospyros que apresenta cerca de 400 espécies, distribuídas em 15 seções. Está representado no Brasil por aproximadamente 35 espécies (Barroso
1978) compreendidas em 6 seções: Danzleria, Paralia, Ermellinus, Rospidios, Cavanillea e Patonia.

No estado do Rio de Janeiro o gênero Diospyros é o único representante da família. Possui 3 espécies: D. ebenaster Retz., D. inconstans Jacq. e D. janeirensis Sandwith. A pesquisa reuniu informações que possibilitaram descrições completas dos táxons tratados. Os autores (Linnaeus 1754, Jacquin 1753, Aublet 1775, Gaertner 1788, Rafinesque 1838, A. De Candolle 1844, Miquel 1856, Bentham \& Hooker 1873, Gürke 1891, Cavalcante 1963) que anteriormente pesquisaram o gênero, fizeram descrições incompletas das espécies.

Neste trabalho, procurou-se aprofundar os conhecimentos das características de nervação das folhas, dos tipos de

*Dissertação de mestrado apresentada ao curso de Pós-graduação em Ciências Biológicas (Botânica) da Universidade Federal do Rio de Janeiro/ Museu Nacional no ano de 1996, orientada pela Dra. Graziela Maciel Barroso, sob o título Diospyros Dalech. ex L. (Ebenaceae) do estado do Rio de Janeiro.

${ }^{1}$ Bolsista da Coordenação de Aperfeiçoamento de ensino superior - CAPES 
inflorescências e da morfologia das flores e dos frutos, visando facilitar o reconhecimento de espécimes em estado vegetativo e reprodutivo.

As espécies ocorrem na Floresta Atlântica e Restinga, tendo sido observadas tanto em formações primárias como em degradadas.

\section{HISTÓRICO}

Linnaeus (1754), em sua obra Genera Plantarum, apresentou o gênero Diospyros que já havia sido descrito por Dalechamp em 1587 (apud Linnaeus, 1754). Este gênero foi criado a partir da espécie Diospyros lotus L. O nome Diospyros significa "fruto dos deuses".

Jacquin (1763) descreveu e ilustrou a espécie Diospyros inconstans.

Aublet (1775) classificou o gênero Paralea baseado na flor masculina de Paralea guianensis, que foi descrita e ilustrada em sua obra Plantas da Guiana Francesa.

Gaertner (1788) fez a classificação do gênero Embryopteris onde descreveu e ilustrou o fruto, a semente e o embrião da espécie Embryopteris peregrina.

Rafinesque (1838), ao estudar as árvores e arbustos da América do Norte, classificou 2 gêneros: Mabola e Persimon. Fez as novas combinações Mabola edulis e Persimon virginiana, baseadas em Diospyros Mabola e Diospyros virginiana, respectivamente. Justificou a criação dos gêneros devido ao "extraordinário número e diferente posição das anteras" de Diospyros Mabola à Diospyros virginiana que apresentava 16 estames em 2 séries, o que as diferenciava de Diospyros lotus que possuía 8 estames em 1 série.

A. De Candolle (1844) apresentou um trabalho detalhado em Prodromus onde tratou a família Ebenaceae com 8 gêneros: Royena, Euclea, Gunisanthus, Rospidios, Macreightia, Diospyros, Maba e Cargillia. Manteve os gêneros Royena e Euclea, criados por Linnaeus (1754). Considerou Dalechamp autor do gênero Diospyros. Sinonimizou o gênero Paralea criado por Aublet (1775) com
Diospyros, e o colocou na secção EuDiospyros, visto que sua morfologia se assemelhava à dessas espécies. Considerou também como pertencente ao gênero Diospyros a espécie Embryopteris peregrina, criada por Gaertner (1788). Manteve o gênero Cargillia, criado por Robert Browm em 1810 (apud De Candolle 1844). Não considerou as modificações feitas por Rafinesque (1838). Manteve o gênero Maba Fort. Criou os gêneros Gunisanthus e Rospidios, utilizando como basiônimo Diospyros pilosula e Diospyros vaccinoides, respectivamente, tendo como novas combinações Gunisanthus pilosulus e Rospidios vaccinoides. Descreveu Macreightia nessa ocasião, composto por 7 novas espécies. Dividiu o gênero Diospyros em 4 seções: TetraDiospyros, Otogyne, EuDiospyros e Amuxis. Esse trabalho constou somente de descrições, não contendo ilustrações das espécies.

Miquel (1856), na Flora Brasiliensis de Martius, incluiu em Diospyros os gêneros Guajacana, Hebenaster, Paralea, Cavanillea e Embryopteris. Adotou Dalechamp como autor de Diospyros e do gênero Macreightia de De Candolle. Fez a apresentação de mais 3 gêneros: Diclidanthera, Moutabea e Hornschuchia. Elaborou pela primeira vez uma chave analítica para os gêneros austro-americanos da família Ebenaceae, baseado somente no número de verticilos protetores.

Bentham \& Hooker (1873) consideraram 6 gêneros: Royena, Euclea, Maba, Diospyros, Tetraclis e Brachynema. Excluíram Moutabea e Hornschuchia que pertenciam às famílias Polygalaceae e Annonaceae, respectivamente. Incluíram Macreightia em Maba. Apresentaram Diospyros com 15 seções: Melonia, Ebenus, Noltia, Gunisanthus, Guaiacana, Cunalonea, Ermellinus, Patonia, Leucoxylum, Danzleria, Paralea, Cargillia, Rospidios, Cavanillea, Amuxis, anteriormente tratados como gêneros.

Gürke (1891) tratou a família Ebenaceae com 5 gêneros Royena, Euclea, Maba, 
Diospyros e Tetraclis. Considerou Dalechamp autor de Diospyros. Sinonimizou os gêneros Cargillia, Leucoxylum, Noltia, Gunisanthus e Rospidios com Diospyros. Manteve as 15 seções de Bentham \& Hooker (1873). Apresentou 2 gêneros duvidosos para Ebenaceae: Brachynema e Raphidanthe. Elaborou uma chave analítica de gênero, baseada em vários caracteres. Pela primeira vez, foi feita uma chave analítica das seções do gênero Diospyros.

Angely (1917), na flora do estado de São Paulo, tratou o gênero Diospyros como de autoria de Linnaeus, e considerou Maba um gênero distinto.

Irmão Augusto (1946), ao fazer a flora do Rio Grande do Sul, elaborou uma chave de gênero baseada no número de verticilos protetores e de lóculos do ovário.

Sandwith (1949), ao estudar a coleção de Ducke de Diospyros da Amazônia, não reconheceu Maba como um gênero distinto, considerando-o sinônimo de Diospyros. Descreveu a espécie Diospyros janeirensis, baseado na coleta de J. G. Kuhlmann $n^{\circ}$ 507, do Morro Mundo Novo, cujos exemplares tipo encontram-se depositados nos herbários de Kew e do Jardim Botânico do Rio de Janeiro. Neste trabalho não fez ilustrações, nem chave analítica.

Howard (1961) e Howard \& Norlindh (1962) resolveram problemas nomenclaturais que envolviam a espécie Diospyros ebenaster. No primeiro trabalho fez uma revisão das publicações para esta espécie, citou as espécies próximas com suas sinonímias, apresentou fotografias de material tipo. Na segunda publicação diferenciam Diospyros ebenum de Diospyros ebenaster, apresentam fotografias de manuscritos e material tipo.

Cavalcante (1962) apresentou a família com 5 gêneros: Royena, Euclea, Maba, Diospyros e Tetraclis. Adotou o autor Dalechamp para o gênero Diospyros. Citou a tendência de redução a 4 gêneros, pela inclusão de Maba em Diospyros, segundo estudos de Mild-Braed \& Brink (apud
Cavalcante 1962) e Sandwith (1949). Elaborou uma chave analítica para as seções do gênero Diospyros baseada na forma e número de lobos da corola; pilosidade e número de lóculos do ovário; pilosidade e número de estames e nas nervuras laterais; além de apresentar uma chave analítica para as espécies ocorrentes na Amazônia.

Engler (1964) considerou 4 gêneros: Royena, Euclea, Diospyros, Tetraclis. Incluiu Maba em Diospyros. Elaborou chave analítica para as famílias da ordem Ebenales.

Harley \& Mayo (1980) fizeram uma listagem das espécies ocorrentes na Bahia e consideraram Linnaeus como o criador do gênero.

Cronquist (1981) apresentou a família Ebenaceae com 5 gêneros: Diospyros, Euclea, Rhaphidanthe, Royena e Tetraclis. Elaborou chave analítica para as famílias da ordem Ebenales.

Reitz (1988), ao tratar da família Ebenaceae na Flora de Santa Catarina, considerou Linnaeus autor do gênero Diospyros, manteve o gênero Maba como sinônimo de Diospyros, apresentou descrição e ilustrações detalhadas de Diospyros inconstans. Tratou também da espécie cultivada Diospyros kaki que foi descrita e ilustrada com pouco detalhamento.

No decorrer deste trabalho foi possível perceber que alguns pesquisadores consideraram Dalechamp autor do gênero Diospyros (De Candolle 1844, Gürke 1891, Irmão Augusto 1946, Cavalcante 1962) e outros consideraram Linnaeus (Bentham \& Hooker 1873, Angely 1917, Harley \& Mayo 1980, Reitz 1988). De posse das publicações ficou constatado que segundo às normas atuais de nomenclatura, a maneira correta de citar o autor seria Dalechamp ex Linnaeus. Dalechamp foi o primeiro a descrever o gênero em 1587, data que invalidaria a sua publicação, porém Linnaeus (1754) em sua obra Genera Plantarum redescreve o gênero e cita Dalechamp como autor. 


\section{MATERIAL E MÉTODOS}

Este trabalho constou inicialmente de levantamento bibliográfico, principalmente nas bibliotecas do Jardim Botânico do Rio de Janeiro, Museu Nacional e Biblioteca Nacional. Paralelamente foram consultados os seguintes herbários: Departamento de Botânica do Museu Nacional do Rio de Janeiro (R), Jardim Botânico do Rio de Janeiro (RB), Herbário "Alberto Castellanos" - FEEMA (GUA), Herbarium Bradeanum (HB), Universidade Santa Úrsula (RUSU) e Universidade Federal Rural do Rio de Janeiro (RBR). Os herbários consultados apresentavam coleções pequenas e pouco representativas, sendo que o Herbarium Bradeanum (HB), a Universidade Federal Rural do Rio de Janeiro (RBR) e a Universidade Santa Úrsula (RUSU), não possuíam coletas do Rio de Janeiro. As coleções referentes à família foram analisadas e os materiais referentes ao Estado do Rio de Janeiro selecionados. Além do material herborizado, foi utilizado material fresco e fixado em álcool a $50 \%$ ou a $70 \%$. Todo material foi observado em laboratório e comparado com as referentes diagnoses. No Jardim Botânico do Rio de Janeiro os projetos Restinga, Flora do Estado do Rio de Janeiro e Mata Atlântica, auxiliaram bastante na ampliação das coleções do gênero do acervo desta Instituição. A pesquisa abrangeu excursões ao campo no estado do Rio de Janeiro para coleta e observação das espécies, além de registros fotográficos.

Foi elaborada uma chave para identificação das espécies ocorrentes no Estado do Rio de Janeiro, baseada nos caracteres vegetativos e reprodutivos. Os termos morfológicos foram baseados em Stearn (1966), e as formações vegetais em Rizzini (1979). Além da descrição do gênero e das 3 espécies este trabalho abrangeu o levantamento dos nomes vulgares, utilidades, épocas de floração e frutificação, habitat, dados ecológicos e citação de material examinado, de cada entidade, através de pesquisa bibliográfica e de material de herbário. Para cada espécie foi feito também um estudo comparativo dos padrões de venação das folhas, dos tipos de inflorescências e da morfologia das flores e frutos. Todas as espécies foram plotadas em um mapa do estado do Rio de Janeiro.

Para observações da organização da rede de nervuras, folhas inteiras foram diafanizadas e coradas pela safranina (Strittmater 1973). O padrão de venação foi identificado segundo Hickey (1973). As denominações referentes às inflorescências basearam-se em Troll (1969). O tipo de fruto foi classificado de acordo com a proposta de Barroso et al. (Inédito).

Foram organizadas tabelas de épocas de floração e frutificação das espécies, baseadas nas informações retiradas das etiquetas de herbários, e também uma listagem dos coletores, seus números e espécies correspondentes.

Para a espécie cultivada, estudada separadamente, foram abordados os seguintes aspectos: origem, nome vulgar, época de floração e frutificação, utilidade, descrição da espécie e citação do material examinado.

As obras e periódicos foram citados segundo Stafleu (1967) e Lawrence et al (1968), e as abreviaturas dos nomes dos autores seguiram Brummit \& Powell (1992).

As abreviaturas utilizadas no texto significam: fl. (flor), fr. (fruto), ms.m.(metros sobre a superfície do mar), compr. (comprimento), larg. (largura), cm (centímetro), $\mathrm{s} / \mathrm{n}^{\mathrm{o}}$ (sem número de coleta), g (grama), mg (miligrama), mcg (micrograma) e UI (Unidade Internacional).

\section{RESULTADOS MORFOLOGIA}

\section{Folhas}

Todas as espécies possuem folhas alternas, simples, pecioladas. A lâmina é oblonga ou lanceolada em D. ebenaster (Fig. 1a), obovada em D. inconstans (Fig.1b) e 
lanceolada em D. janeirensis (Fig.1c). A margem apresenta-se inteira nas 3 espécies, com ápice obtuso em D. ebenaster (Fig. 1a), obtuso, emarginado ou truncado em $D$. inconstans (Fig. 1b) e agudo em $D$. janeirensis (Fig. 1c) e base curtamente atenuada em $D$. ebenaster (Fig. 1a), cuneada em $D$. inconstans (Fig. 1b) e aguda em $D$. janeirensis (Fig. 1c). Caracteriza-se por apresentar uma nervura principal mais espessa que as demais nervuras. Da nervura principal, partem obliquamente, nervuras mais tênues que formam grandes arcos na lateral das folhas. Acima destes arcos inicia-se a formação de arcos menores. As nervuras terciárias são anastomosadas formando retículos. Este padrão de venação chama-se camptobroquidódromo, sendo encontrado nas 3 espécies estudadas.

\section{Inflorescências}

Este trabalho classificou a inflorescência de Diospyros como derivada de um tirsóide múltiplo, no qual a zona de enriquecimento sofreu uma redução pelo encurtamento de nós e entrenós e perda de flores nos paracládios.

A inflorescência de Diospyros pode terminar por uma flor (monotrióide) ou perder a flor terminal por truncamento. Os paracládios com flores dispostas em cincínios localizamse nas axilas de brácteas foliares, e são denominados frondosos.

A inflorescência perfeita de $D$. ebenaster apresenta eixo glabro de 15,0-25,0 cm de compr., terminando em gema pilosa de $0,2 \mathrm{~cm}$ de compr., os ferofilos são alternos, lanceolados ou oblongos de 12,0-19,0 cm de compr. X 3,0$8,0 \mathrm{~cm}$ de larg., base curtamente atenuada, ápice obtuso-acuminado, face adaxial glabra, lâmina lúcida, face abaxial glabra (Fig. 2a). Na axila de cada ferofilo encontra-se o paracládio de 1,0-2,0 cm de compr. com 4 flores de 1,52,0 cm de compr. formando um cincínio (Fig. 2b). Cada flor apresenta 2 bractéolas laminares.

A inflorescência estaminada de $D$. inconstans, apresenta eixo de 10,0-15,0 cm de compr., terminando em gema pilosa de 0,3 cm de compr., ferofilos são alternos, obovados de 4,0-11,0 cm de compr. X 3,0-7,0 cm de larg., base cuneada, ápice obtuso, emarginado ou truncado, face adaxial com lâmina lúcida densamente pontuada, com pouca pilosidade, pêlos longos simples e híspidos, face abaxial pilosa com pêlos simples híspidos (Fig. 2c). Na axila de cada ferofilo encontra-se o paracládio de 1,0-1,5 cm de compr. com uma tríade de flores de 0,7 a 1,0 cm de compr. (Fig. 2d). A inflorescência pistilada é lenticelada, pilosa nos ramos jovens, de $12-25 \mathrm{~cm}$ de compr. terminando em gema pilosa de $0,2-0,4 \mathrm{~cm}$ de compr., ferofilos são alternos, obovados de 5,08,0 cm de compr. X 3,0-5,0 cm de larg., base cuneada, ápice obtuso, emarginado ou truncado, face adaxial com lâmina lúcida densamente pontuada, pouco pilosa, pêlos longos, simples e híspidos, face abaxial pilosa com pêlos simples, híspidos (Fig. 2e). Na axila de cada ferofilo encontra-se um paracládio de 0,8-1,0 cm de compr. com uma única flor (Fig. 2f) apresentando 2 bractéolas laminares.

A inflorescência estaminada de $D$. janeirensis, apresenta eixo piloso de 10,0-22,0 $\mathrm{cm}$ de compr., terminando em uma gema pilosa de $0,3 \mathrm{~cm}$ de compr., ferofilos lanceolados de 7,0-12,0 cm de compr. X 2,5-3,5 cm de larg., base e ápice agudas, face adaxial com pêlos híspidos simples, e abaxial com densos pêlos híspidos simples na nervura central e na margem e esparsos pêlos na lâmina (Fig. $2 \mathrm{~g}$ ). $\mathrm{Na}$ axila de cada ferofilo encontra-se o paracládio de 0,5-0,8 cm de compr. com 5 flores pilosas. Cada flor apresenta de $0,5-1,0 \mathrm{~cm}$ de compr. Da redução da zona de enriquecimento resultou um paracládio de segunda ordem, formando 2 cincínios e terminando em uma flor (Fig. 2h). Na base de cada flor existem 2 bractéolas conchiformes. A inflorescência pistilada é pilosa, de 15,0-20,0 $\mathrm{cm}$ de compr. terminando em gema pilosa de 0,2 de compr. Os ferofilos são alternos, lanceolados de 6-8 cm de compr. X 1,5-2,0 de larg. com base e ápice agudos, face adaxial possui pêlos híspidos simples na nervura central e a abaxial apresenta 


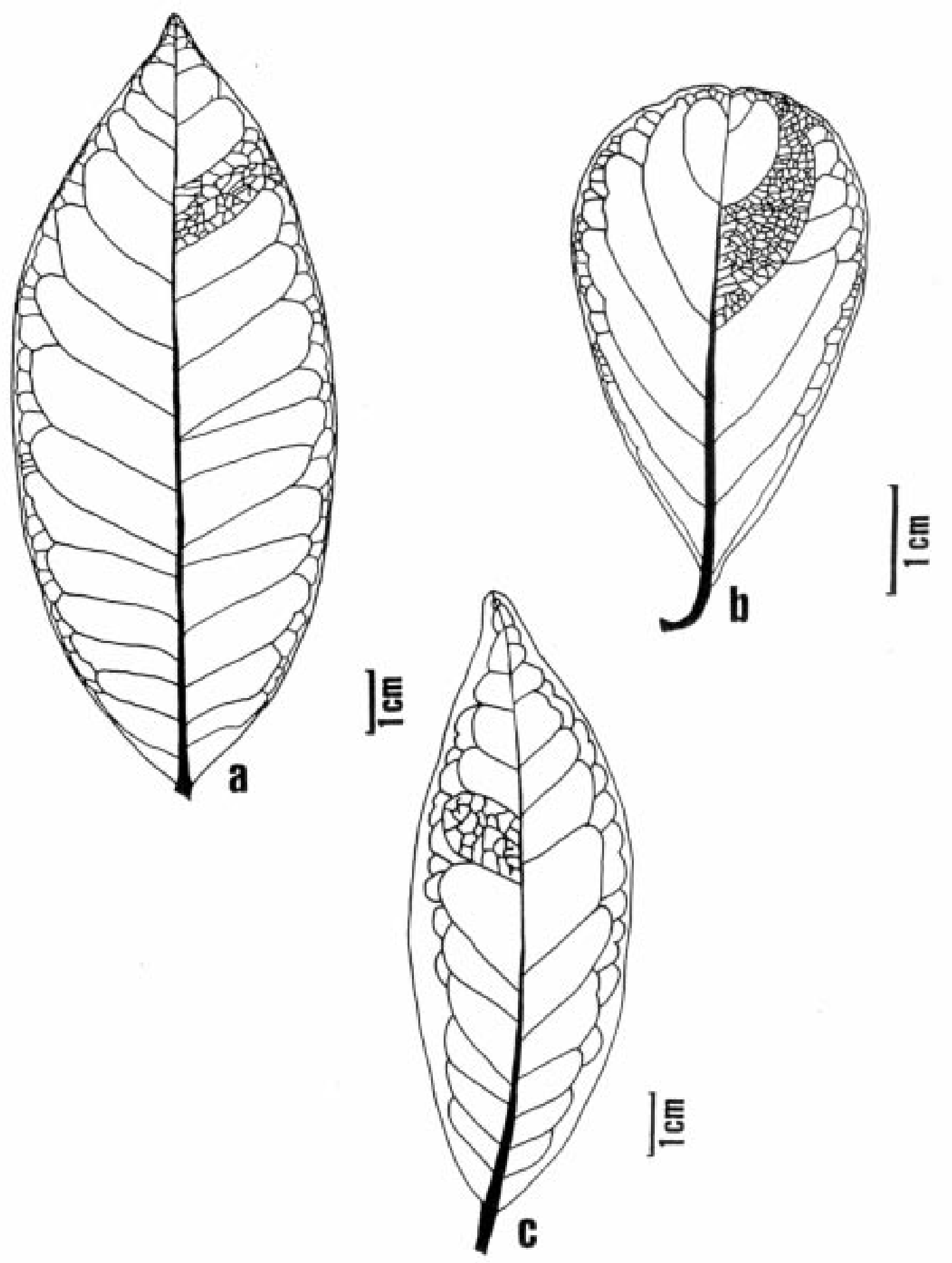

Figura 1: Venação das folhas. a)D. ebenaster; b)D. inconstans; c)D. janeirensis. 


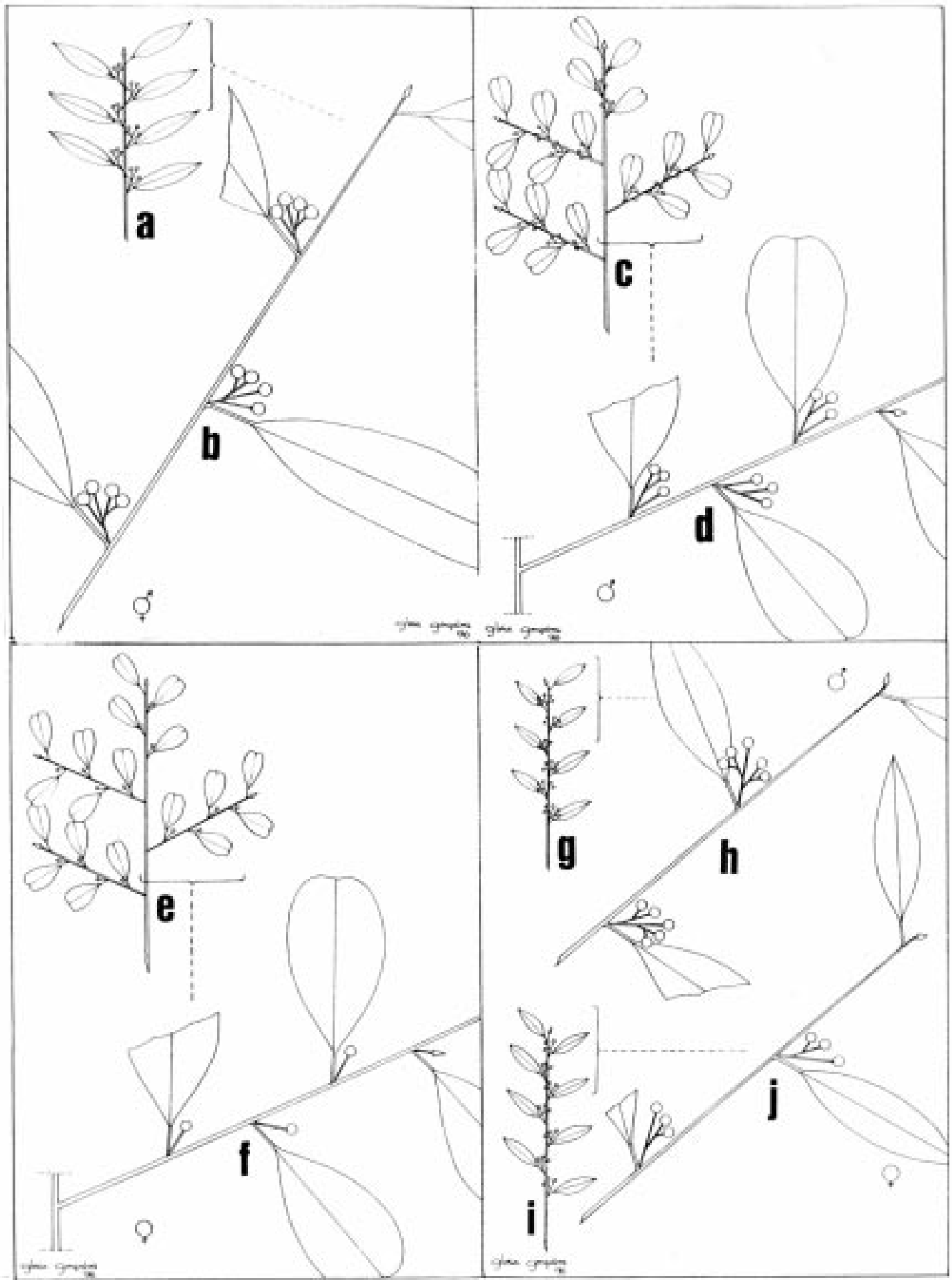

Figura 2: D. ebenaster, a)Esquema da inflorescência perfeita, b)Paracládio com 4 flores formando 1 cincínio; $D$. inconstans, c)Esquema da inflorescência estaminada, d) Paracládio estaminado constituído de 1 tríade, e)Esquema da inflorescência pistilada, f)Paracládio pistilado monotrióide; D. janeirensis, g)Esquema da inflorescência estaminada, h)Paracládio estaminado constituído de 2 cincínios, i)Esquema da inflorescência pistilada, j)Paracládio pistilado constituído de 1 cincínio. 
pêlos na lâmina e pêlos híspidos simples na nervura central e na margem (Fig. 2i). Na axila de cada ferofilo encontra-se o paracládio de 1,0-1,7 cm de compr. com 3 flores bastante pilosas de 1,0-1,7 cm de compr., formando um cincínio (Fig. 2j). Cada flor apresenta 2 bractéolas conchiformes.

\section{Flores}

As inflorescências são pêndulas e localizam-se abaixo das folhas o que dificulta, à primeira vista, ao observador, perceber que a planta está em época de floração. As flores são trímeras em D. inconstans (Fig. 4b), tetrâmeras em D. ebenaster (Fig. 3b) ou pentâmeras em $D$. janeirensis (Fig. 5cd). Nas espécies estudadas foi possível observar que as flores são de 0,7-1,5 cm de compr., coloração alvo-esverdeadas, prefloração torcida e pediceladas. Quanto a sexualidade, as flores são monoclinas em $D$. ebenaster (Fig. 3a) ou diclinas em D. inconstans (Fig. 4cd) e D. janeirensis (Fig. 5cd). Ocorrendo estaminódios nas flores pistiladas e pistilóides nas flores estaminadas. O androceu pode ser formado por 6 estames epipétalos como em D. ebenaster, 12 estames organizados em duas séries como em $D$. inconstans (Fig. 4d) ou mais de 100 estames como em $D$. janeirensis (Fig. 5d). A antera é diteca, tetraesporangiada, basifixa, rimosa, sendo observada em algumas plantas de $D$. inconstans, deiscência no botão. O gineceu é sincárpico, podendo apresentar 8 lóculos em $D$. ebenaster e 6 lóculos em $D$. inconstans e D. janeirensis, contendo apenas 1 óvulo em cada lóculo. O ovário é súpero e piloso, estilete curto, e o estigma é variado, podendo apresentar 4 regiões estigmáticas em $D$. ebenaster (Fig. 3c), 5 regiões estigmáticas em D. janeirensis (Fig. 50c), e 6 regiões estigmáticas em D. inconstans (Fig. 4c).

\section{Frutos}

Os frutos foram classificados em bacóide do tipo campomanesoídeo (Barroso, Inédito). Apresenta cálice persistente e acrescente.
Pericarpo com diferenciação em exocarpo, mesocarpo e endocarpo. O exocarpo pode apresentar superfície lisa como em D. ebenaster (Fig. 3e) e D. inconstans (Fig. 4g) ou apresentar indumentos e rugosidade como em D. janeirensis (Fig. 5f). Mesocarpo pouco desenvolvido em $D$. inconstans e D. janeirensis ou bem desenvolvido em D. ebenaster. Endocarpo pouco definido nas 3 espécies. A porção central do fruto, onde se situam os lóculos, é preenchida por tecido carnoso, uniforme e compacto. Os lóculos apresentam-se com 1 semente cada, bem delimitados, dispostos radialmente. Semente com testa lisa, rafe dorsal, forma achatada, com placentação axial.

Em ovários de D. ebenaster encontrouse 8 lóculos e 8 óvulos, porém nos frutos foi visto que o número de sementes é variável entre 1 e 8 , pois alguns óvulos não se desenvolvem. D. janeirensis possui 6 lóculos e 6 óvulos e em alguns frutos, pode ser observado que algumas sementes iniciam um desenvolvimento, porém ficam reduzidas em relação às outras. Em $D$. inconstans não foi notada redução no número, nem no tamanho das sementes. Nas 3 espécies o endosperma é esbranquiçado, porém foi observado em $D$. inconstans que o contato deste com o ar o torna amarelado. As espécies estudadas apresentam o embrião reto e o cotilédone foliáceo.

\section{TRATAMENTO TAXONÔMICO}

Diospyros Dalech. ex L. Gen. Pl. I. 143. 1754. Dactylus Forssk. Fl. Aegypt. Arab. p. 36. 1775 (apud Cavalcante, 1962)

Paralea Aubl. Pl. Gui. 1:576. t.231. 1775

Embryopteris Gaertn. Fruct. 1:145.t.29. 1788

Cavanillea Desr. in Lam. Encyc. 3:663. 1789 (apud Cavalcante, 1962)

Cargillia R. Br. Prod. 526. 1810 (apud De Candolle, 1844)

Leucoxylum Blume. Bijdr. 1169. 1826 (apud De Candolle, 1844)

Noltia Schummel in Danske. Selsk. Afh. 3. 
1827 (apud De Candolle, 1844)

Patonia Wight Illustr. 1:19. 1838 (apud De Candolle, 1844)

Mabola Raf. Sylva. Tellur. 11. 1838

Persimon Raf. Sylva. Tellur. 164. 1838

Gunisanthus A. DC. in DC. Prod. 8:219. 1844

Rospidios A. DC. in DC. Prod. 8:220. 1844

Danzleria Bert. ex A. DC. in DC. Prod. 8:224. 1844

Árvores de pequeno a grande porte ou arbustos. Folhas alternas, simples; pecíolo de até $2,5 \mathrm{~cm}$ de compr.; lâmina geralmente de margem inteira e pilosa na face abaxial, campto-broquidódromo. Inflorescência botrióide bracteoso, que pode terminar por uma flor ou perder a flor terminal, sendo considerado um ramo truncado; os paracládios na axila de um ferofilo, constituem um cincínio, uma tríade ou um monotrióide. Flores diclinas em plantas dióicas, raro monoclinas, esverdeadas ou alvas; cálice persistente, acrescente, 3-7 lobado; corola simpétala, tubulosa, urceolada, campanulada ou rotada, 3-7 lobada, geralmente pilosa na face externa; androceu constituído de 4 a mais de 100 estames, filetes conatos na base, anteras tetrasporangiada linear ou linear-lanceolada, diteca, deiscência longitudinal, raro poro apical. Presença de pistilóide nas flores estaminadas; gineceu sincárpico, ovário súpero globoso ou subgloboso, geralmente piloso, 6-8 lóculos, raro 10, 1 óvulo por lóculo; estilete terminal curto, estigma ramificado ou lobado. Presença de estaminódios nas flores pistiladas. Fruto bacóide globoso, subgloboso, glabro ou pubescente tipo campomanesoídeo; semente 1-8, oblonga, achatada, testa lisa, rafe dorsal evidente; endosperma esbranquiçado às vezes ruminado, com reserva de hemicelulose e óleo; embrião reto ou curvo, cotilédones foliáceos.

\section{CHAVE ANALÍTICA PARA RECONHECIMENTO DAS ESPÉCIES DO ESTADO DO RIO DE JANEIRO}

1 - Plantas monoclinas com flores tetrâmeras, androceu com 6 estames, gineceu com ovário octa-locular; folha oblonga ou lanceolada.

Diospyros ebenaster

1'- Plantas sem este conjunto de características.

2 - Inflorescência estaminada com 3 flores (tríade), e pistilada com 1 flor (monotrióide); flores trímeras, androceu com 12 estames; folha obovada................Diospyros inconstans 2'- Inflorescência estaminada com 5 flores ( 2 cincínios), e pistilada com 3 flores ( 1 cincínio); flores pentâmeras, androceu com mais de 20 estames; folha lanceolada

Diospyros janeirensis

\section{DESCRIÇÃO DAS ESPÉCIES}

1- Diospyros ebenaster Retz.Lund Physiogr. Salsk. Handl. 1:176. 1781 (apud Howard 1962); Retz. Obs. Bot. 5:31. 1789 (apud Howard 1962).

D. ebenum Lfil. Suppl. Pl. Syst. Veg. 440. 1781. (apud Howard 1962)

D. glaberrima Rottb, Nye Saml. Kong. Dansk. Vidensk. Selsk. Skr. 2:540. pl.5. 1783. (apud Howard 1962)

D. brasiliensis Mart. Fl. Bras. 7:5. t.2. fig.2. 1856.

Figs. 3abcdefg, 6a e 7.

Árvore ou arvoreta de 6 a $12 \mathrm{~m}$. de altura; tronco com casca lisa, córtex verdeamarelado; ramo cilíndrico, verde, estriado e glabro; gema de 0,2 cm de compr., pilosa. Folha com pecíolo de 1,0-1,5 cm de compr.; lâmina de 12,5-21,0 cm de compr. X 5,0-8,5 $\mathrm{cm}$ de larg., oblonga ou lanceolada coriácea ou subcoriácea, discolor; base curtamente atenuada; ápice obtuso; margem inteira; nervuras salientes na face abaxial, nervação campto-broquidódromo. Inflorescência perfeita, com paracládios de 4 flores, formando um cincínio. Flores de 1,0-1,5 cm de compr., tetrâmeras, esverdeadas. Cálice de 0,4-0,6 cm de compr., com 4 lobos apiculados. Corola de 


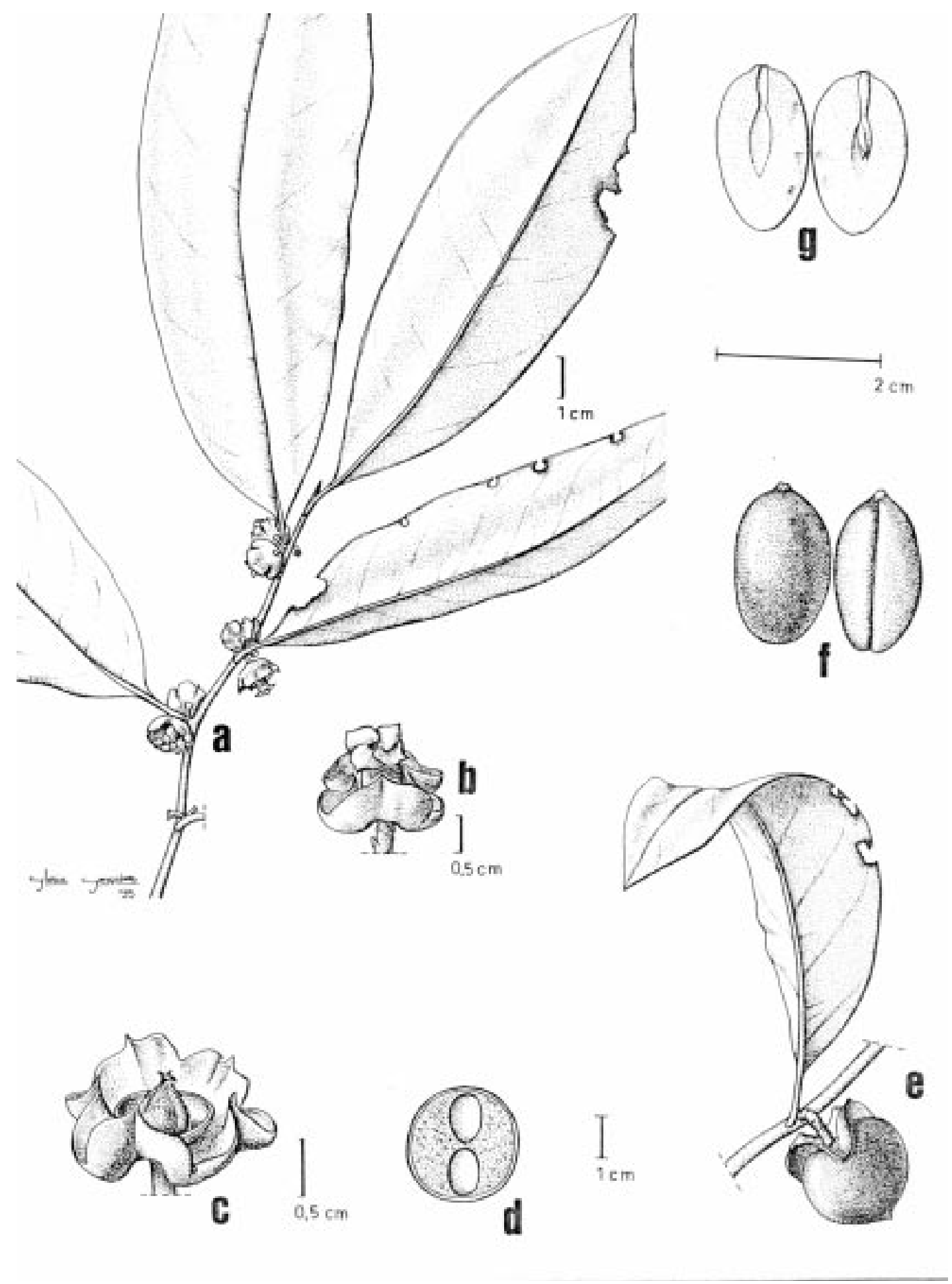

Figura 3: D. ebenaster (L.C.Giordano 1648 e 1822 - RB); a)Inflorescência perfeita, b)Flor perfeita, c)Gineceu, d)Corte transversal do fruto, e)Fruto, f)Semente, aspecto do hilo e rafe dorsal, g)Corte longitudinal da semente, aspecto do embrião. 
0,8-1,0 cm de compr., tubulosa, 4 lobada. Androceu com 6 estames epipétalos, filetes achatados, antera lanceolada. Gineceu com pêlos amarelos, 8 lóculos, placentação apical; 4 regiões estigmáticas. Fruto globoso, de 1,0$1,5 \mathrm{~cm}$ de diâmetro, imaturos esverdeados e maduros nigrescentes, exsudato vinosonigrescente. Sementes de 1-8, de $2 \mathrm{~cm}$ de compr.; testa castanha, embrião reto.

\section{FLORAÇÃO E FRUTIFICAÇÃO}

Floresce no mês de maio e novembro e frutifica em fevereiro, de abril a junho e novembro.

\section{HABITAT}

Floresta Atlântica. Ocorrendo em floresta pluvial baixo montana e floresta pluvial ripária.

\section{DADOS ECOLÓGICOS}

Encontrada de 50 a 300 ms.m.; espécie ciófila, semi-ciófila, heliófila, semi-heliófila, ocorrendo em afloramentos rochosos, em ambientes úmidos e áreas degradadas.

\section{COMENTÁRIOS}

O epíteto ebenaster do latim flor preta, está relacionado ao fato das flores esverdeadas tornarem-se pretas no material herborizado. É conhecida popularmente pelo nome de Sapotapreta. Quanto à utilidade, foi constatado num estudo referente à atividade antimicrobiana de plantas vasculares, que esta espécie em extrato de etanol, possui atividade para Mycobacteria, nas folhas e frutos. (Nickell 1959)

\section{MATERIAL EXAMINADO}

Rio de Janeiro: Município de Angra dos Reis, Ilha Grande, Reserva Biológica Estadual da Praia do Sul, caminho para Simão Dias, D. S. D. Araújo 6123 (fr.), 16.02.1984 (GUA); ibidem, idem, Praia do Sul, D. S. Pedrosa 1118 et H. Q. B. Fernandes 926 (fr.), 13.06.1984 (GUA); ibidem, idem, morro atrás do costão ,
D. S. D. Araújo 6687, et al (fr.), 26.11.1985 (GUA); Município de Paraty, Morro do Corisco, R. Marquete 967 et al. (fr.), 20.04.1993 (RB); ibidem, Praia dos Antigos, APA-Cairuçu, R. Marquete 1610 (fr.), 13.04.1994 (RB); ibidem, Laranjeiras, Caminho da Praia do Sono, APA-Cairuçu, R. Reis 128 et al (fl., fr.), 12.05.1994 (RB); ibidem, Ponte do Rio dos Meros, APA-Cairuçu, L. C. Giordano 1648 et al (fr.), 11.06.1994 (RB); ibidem, Rio dos Meros, APA-Cairuçu, L. C. Giordano 1822 et al (fl.), 29.11.1994 (RB); ibidem, idem, L. C. Giordano 2091 et al. (fl.), 05.12.1995 (RB); Município do Rio de Janeiro, cultivada, A. Ducke s/ no (fl.),11.1928 (RB); Município de Silva Jardim, Rebio Poço das Antas, D. S. Farias 311 et al (fr.), 01.09.1994 (RB).

2- Diospyros inconstans Jacq. Enum. Syst. Plant. Insul. Caribaeis 34. 1760; Select. Stirp. American. Hist. 276, lâm. 174. fig. 67. 1763; Burkart, Flora Il. Entre Rios 5:27-31, figs. 8-9. 1979; Reitz, Klein \& Reis, Sellowia 28-30: 23. 1978; Reitz, Klein \& Reis, Sellowia 34-35:31. 1983.

Macreightia inconstans (Jacq.) A. DC., Prodr. Syst. Nat. 8:221. 1844.

Maba inconstans (Jacq.) Griseb., Fl. Brit. West Indian Islands 404. 1864.

\section{Figs. 4abcdefghi, $6 \mathrm{~b}$ e 7.}

Árvore ou arbusto decumbente ou semiescandente, de 2 a $10 \mathrm{~m}$. de altura; tronco acinzentado, estriado; ramo piloso quando jovem e glabro quando adulto, cilíndrico com lenticelas; gema de $0,3 \mathrm{~cm}$ de compr., pilosa. Folhas com pecíolo de 0,3-0,8 cm de compr.; lâmina de 5,0-11,0 cm de compr. $X 3,0-7,0 \mathrm{~cm}$ de larg., obovada, subcoriácea, discolor, lustrosa na face adaxial e glabra a pubescente na face abaxial, base cuneada, ápice obtuso, emarginado ou truncado; nervuras salientes na face abaxial. Inflorescência estaminada com paracládios contituídos por uma tríade de flores. Inflorescência pistilada com paracládios com uma flor (monotrióide). Flores trímeras, 

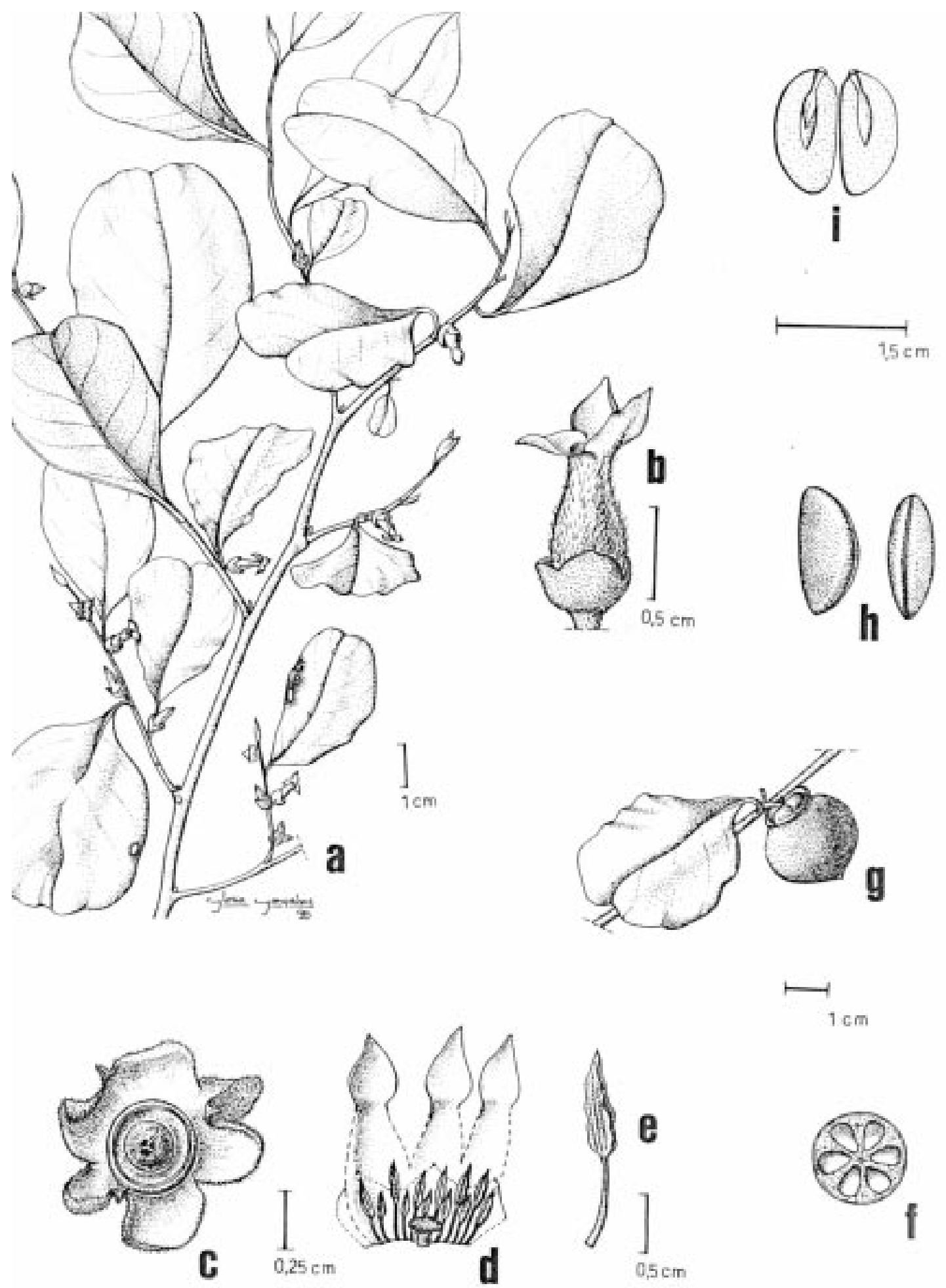

Figura 4: D. inconstans, (R.C.Lopes 70 e 71- RUSU); a)Inflorescência pistilada, b)Flor pistilada, c)Gineceu, d)Corte longitudinal da flor estaminada, e)Estame, f)Corte transversal do fruto, g)Fruto, h)Semente, aspecto da rafe dorsal, i)Corte longitudinal da semente, aspecto do embrião . 
diclinas, em plantas dióicas, pêndulas. Flores estaminadas de 0,8-1,3 cm de compr., esverdeadas, pilosa na face externa, pêlos brancos brilhosos, amarelados quando secas; pedicelo de 0,2-0,3 cm de compr. Cálice de 0,3-0,4 cm de compr., com 3 lobos. Corola de 0,8-1,0 cm de compr., tubulosa, 3 lobada. Androceu com 12 estames, heterodínamos, organizados em 2 séries, os menores mais próximos ao pistilóide, os maiores mais próximos a fauce, filetes conatos na base 2 a 2; antera com grão de pólen alvo luzidio. Flores pistiladas de 1,0-1,5 $\mathrm{cm}$ de compr., esverdeadas, pilosas na face externa. Cálice de 0,5-0,7 cm de compr. Corola de 0,5-1,0 cm de compr. Gineceu com ovário de 6 lóculos, placentação apical; 6 regiões estigmáticas. Fruto de 0,5-1,0 cm de compr., globoso, glabro, indeiscente, imaturo verde, passando por vináceo, tornando-se negro quando maduro. Semente 6 de 0,8-1,5 cm de compr.; testa castanha; embrião reto.

\section{FLORAÇÃO E FRUTIFICAÇÃO}

Floresce nos meses de fevereiro, outubro e novembro, frutifica de janeiro a março, maio, julho e agosto.

\section{HABITAT}

Restinga. Ocorrendo em dunas fixas.

\section{DADOS ECOLÓGICOS}

Espécie heliófila, podendo também ser ciófila, ocorrendo em matas de restinga, mesmo quando estas encontram-se degradadas, ou em áreas de restinga arbustiva aberta e fechada. Visitada por formigas, que ocorrem em todas as partes da planta.

\section{COMENTÁRIOS}

O epíteto inconstans do latim inconstante, variável, está relacionado às diferentes formas que a lâmina das folhas desta espécie pode apresentar, variando desde obovada a elíptica com ápice obtuso, emarginado ou truncado. É conhecida popularmente pelos nomes fruta-dejacu-macho, fruta-de-jacu-do-mato, mariapreta, cerejeira-do-mato, cinzeiro. A madeira é utilizada como lenha, e também na confecção de cabos de ferramentas e fueiros, estaca que serve para amparar a carga do carro de bois (Reitz 1988). Os frutos são comestíveis, adocicados, com pouca polpa, sendo por isto especialmente procurados pelas aves como jacus e aracuãs (Reitz 1988). Possui um potencial ornamental, devido a forma da copa, larga e arredondada, e a coloração dos frutos nos seus diferentes estágios de desenvolvimento, que dura de 9-10 meses, tornando-a muito apropriada para a arborização urbana nos logradouros públicos (Reitz 1988, Sanchotene 1985).

\section{MATERIAL EXAMINADO}

Rio de Janeiro: Município de Cabo Frio, $9 \mathrm{Km}$ ao norte do Rio Una, D. S. D. Araújo 6655 et al (fr.), 14.02.1985 (GUA); ibidem, Cia. Salinas Perynas, orla, D. S. D. Araújo 8732 (fr.), 22.02.1989 (GUA); ibidem, idem, próxima à praia do Sudoeste, C. Farney 2273 (fr.), 18.03.1989 (RB); Município de Casimiro de Abreu, Praia Brava, D. S. D. Araújo 7508 et al(fr.), 28.05.1986 (GUA); Município de Macaé, Lagoa Carapebus, D. S. D. Araújo 8453 (fr.), 21.01.1988 (GUA); ibidem, Ilha de Santana, no final da praia, D. S. D. Araújo 8659 et al (fl.), 16.11.1988 (GUA); ibidem, Lagomar, próximo a rodovia, D. S. D. Araújo 10189 (fl.), 30.11 .1994 (GUA); Município de Maricá, Praia de Itacoatiara, J. G. da Silva s/ $\mathrm{n}^{\circ}$ (fl.), 21.10.1982 (R); ibidem, Barra de Maricá, D. S. D. Araújo 5387 et al. (fr.), 13.01.1983 (GUA); ibidem, Restinga de Maricá, Alfonse $\mathrm{s} / \mathrm{n}^{\circ}$ et al. (fr.), 03.1989 (R); ibidem, Restinga da praia de Itaipuaçu, R. C. Lopes 69 et al. (fl., fr.), 25.02.1995 (RB); ibidem, idem, R. C. Lopes 70 et al. (fl.), 25.02.1995 (RB); ibidem, idem, R. C. Lopes 71 et al. (fl., fr.) 25.02.1995 (RB); ibidem, 
idem, R. C. Lopes 72 et al. (fl.) 25.02.1995 (RB); Município de Saquarema, Restinga de Massambaba, próximo à praia de Itaúna, $\mathrm{C}$. Farney 1139 et al.(fr.), 05.08.1986 (RB, GUA); ibidem, Comorros da Lagoa Vermelha, orla, D. S. D. Araújo 9298 (fr.), 26.03.1991 (GUA); ibidem, próximo ao Sambaqui da Beirada, D. S. D. Araújo 9316 (fr.), 27.03.1991 (GUA); ibidem, Reserva Ecológica Estadual de Jacarepiá, C. Farney 2781 et al. (fl.), 29.10.1991 (RB); Município de São João da Barra, Grussai, D. S. D. Araújo 8831 (fr.), 16.05.1989 (GUA); ibidem, Praia Samambaia, próximo ao pasto, D. S. D. Araújo 10059 et al. (fr.), 19.05.1994 (GUA); Município de São Pedro da Aldeia, Morro da Farinha, à Margem da Lagoa de Araruama, D. S. D. Araújo 8984 et al. (est.), 01.06.1989 (GUA); Município de Teresópolis, Santa Rita, Smo Tato $\mathrm{s} / \mathrm{n}^{\mathrm{o}}$ (fr.), 04,07.1945 (RB).

\section{3- Diospyros janeirensis Sandwith Kew.} Bull. 4: 487.1949.

\section{Figs. 5abcdefghi, 6c e 7.}

Árvore ou arvoreta de 5 a 8 m. de altura; ramo cilíndrico, glabro quando adulto e com pêlo amarelado quando jovem; gema de 0,1 cm de compr., pilosa. Folhas com pecíolo de 0,5-0,8 cm de compr.; lâmina de 7,0-12,0 cm de compr. X 2,5-3,5 cm de larg., lanceolada, cartácea, discolor, lustrosa na face adaxial, com pêlos híspidos na nervura central e pilosa na face abaxial com adensamento de pêlos híspidos simples, na nervura central e na margem; base e ápice agudos, às vezes com presença de acúmen no ápice; nervura pouco nítida. Inflorescência estaminada com paracládios de 5 flores, formando 2 cincínios terminados em uma flor. Inflorescência pistilada com paracládios de 3 flores, formando um cincínio. Flores diclinas, em plantas dióicas. Flores estaminadas de $0,8-1,0 \mathrm{~cm}$ de compr., esverdeadas, pedicelos de até $0,5 \mathrm{~cm}$ de compr.; com 2 bractéolas conchiformes pilosas de 0,1-0,5 cm de compr. Cálice de 0,3-0,4 cm de compr., piloso, 5 lobos triangulares- lanceolados. Corola de 0,3-0,8 cm de compr., tubulosa, lobos ovado-oblongo, externamente glabrescente na porção sub-mediana, pêlos amarelados. Androceu com mais de 100 estames, filete variavelmente coato de $0,1 \mathrm{~cm}$ de compr., antera de 0,3-0,5 $\mathrm{cm}$ de compr., pilosa. Flores pistiladas de 1,0-1,3 cm de compr., pedicelo de até $0,8 \mathrm{~cm}$ de compr., presença de 2 bractéolas conchiformes pilosas de 0,2 cm de compr. Cálice de 0,5-1,0 cm de compr., com pêlos amarelos, 5 lobos triangularlanceolados. Corola de 0,5-1,0 cm de compr., tubulosa com faixas medianas de pêlos amarelos nos lobos. Gineceu com ovário piloso, 6 lóculos; 5 regiões estigmáticas. Fruto bacóide, de 1,5-4,0 cm de diâmetro, globoso, com pêlos amarelos e rugosidade. Sementes de até $1,5 \mathrm{~cm}$ de compr.; embrião de $0,6 \mathrm{~cm}$ de compr., reto.

\section{FLORAÇÃO E FRUTIFICAÇÃO}

Floresce de outubro a janeiro, frutifica em outubro e de janeiro a abril.

\section{HABITAT}

Floresta Atlântica, ocorrendo em floresta pluvial baixo montana e Restinga, ocorrendo em dunas fixas.

\section{DADOS ECOLÓGICOS}

Ocorre em mata de encosta, e nas restingas, em mata baixa e arbustiva fechada.

\section{COMENTÁRIOS}

O epíteto janeirensis se deve ao fato de ser uma planta coletada somente no estado do Rio de Janeiro.

\section{MATERIAL EXAMINADO}

Rio de Janeiro: Município de Macaé, Restinga de Cabiúnas, D. S. D. Araújo 5931 et al. (fr.), 19.01.1984 (GUA); Município de 


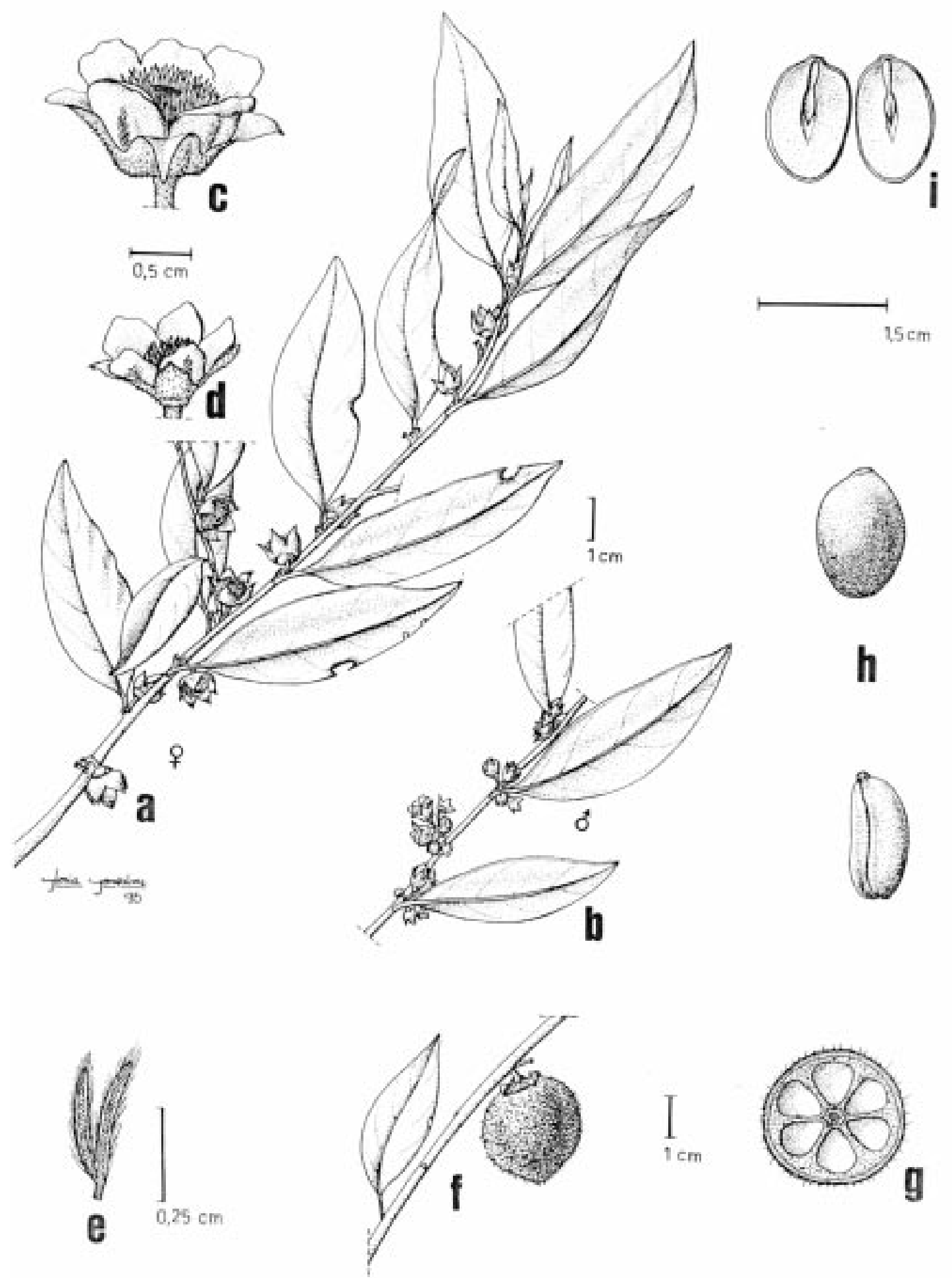

Figura 5: D. janeirensis (J.G.Kuhlman 507- RB e C.Farney 3141 - RB); a)Inflorescência pistilada, b)Inflorescência estaminada, c)Flor pistilada, d)Flor estaminada, e)Estames, f)Fruto, g)Corte transversal do fruto, h)Semente, aspecto do hilo e rafe dorsal; i)Corte longitudinal da semente, aspecto do embrião. 


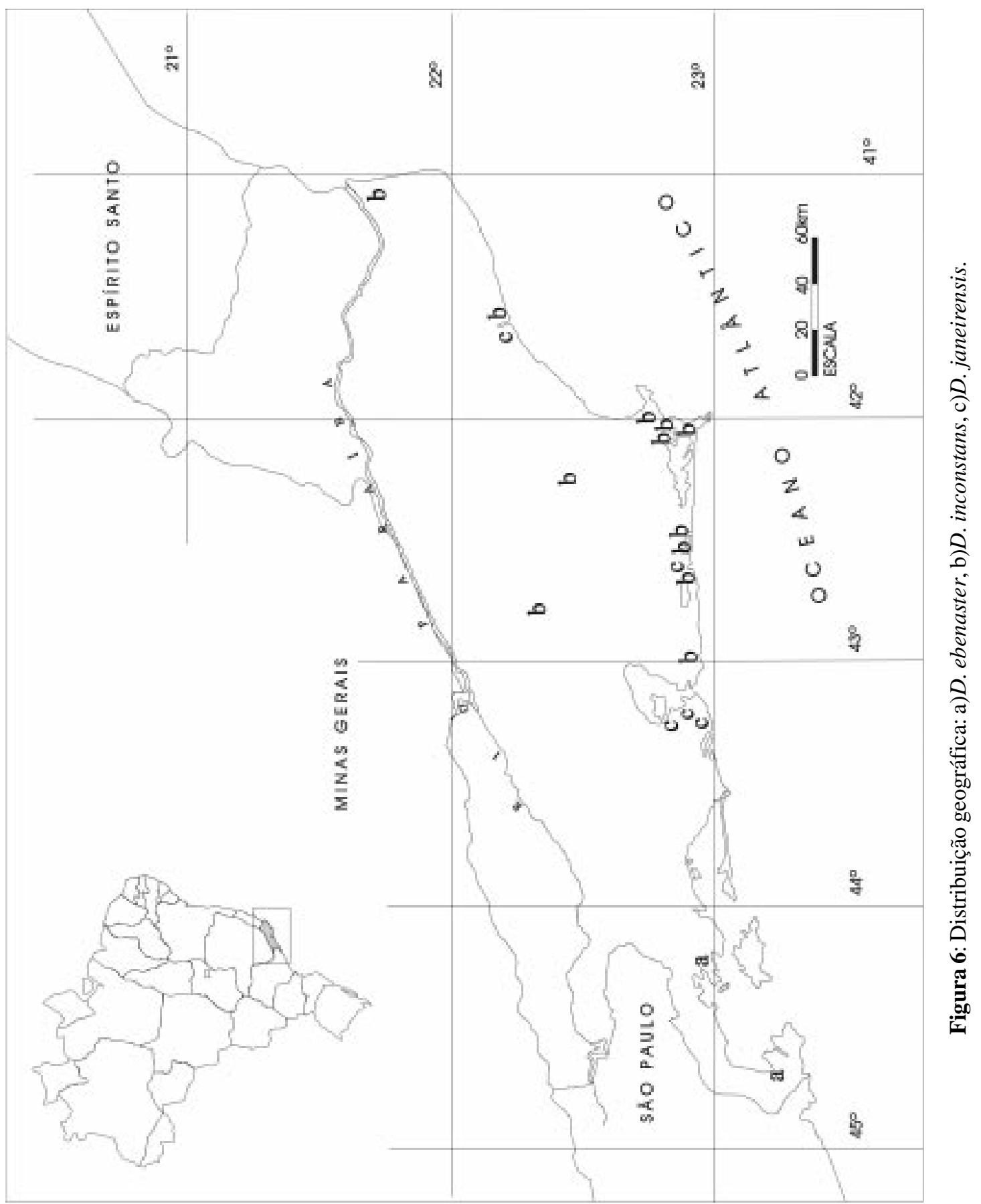


Maricá, Barra de Maricá, D. S. D. Araújo 6995 et al (fl., fr.), 23.10.1985 (GUA); ibidem, Área de Proteção Ambiental, à leste do Morro do Mololo, D. S. D. Araújo 7404 et al. (fr.), 25.04.1986 (GUA); ibidem, idem, Restinga, D. S. D. Araújo 9092 et al. (fr.), 01.03.1990 (GUA); Município do Rio de Janeiro, Morro Mundo Novo, Botafogo, J. G. Kuhlmann 507 (fl.), 13.01.1920 (RB); ibidem, idem, J. G. Kuhlmann s/no (fl.), 21.12.1920 (RB); ibidem, idem, J. G. Kuhlmann s/no(fl.), 11.11.1921 (RB); ibidem, Dois Irmãos, A. Duarte 328 (veget.), 26.09.1946 (RB); ibidem, Matas da Vista Chinesa, C. de Almeida s/n ${ }^{\circ}$ (fr.), 14.02.1954 (RB); Município de Saquarema, Reserva Ecológica Estadual de Jacarepiá, Restinga de Ipitangas, C. Farney 3141 et al. (fr.), 25.04.1992 (RB).

\section{4- ESPÉCIE CULTIVADA}

\section{Diospyros kaki Lfil}

Fig. 8abcd.

No Rio de Janeiro encontra-se Diospyros kaki em extensas áreas de cultivo, nas regiões do Grande Rio e regiões serranas. Trata-se de uma planta exótica originária da
China, Coréia e do Japão (Reitz 1988).

Árvore frutífera muito cultivada no Brasil, onde um grande número de variedades foram introduzidas do Japão, constituindo sua cultura, em larga escala, principalmente nos Estados do Rio de Janeiro, São Paulo e Minas Gerais, até o Rio Grande do Sul (Corrêa 1984).

É conhecida popularmente pelos nomes: caqui, caquieiro, caquizeiro, caqui-do-japão, kaki-do-japão, kakieiro, kakizeiro (Pio Corrêa 1984). O nome Caqui em japonês significa amarelo-escuro, e está relacionado à cor do fruto (Balbach 1957).

Floresce nos meses de setembro e outubro, e possui frutos maduros de março a abril (Reitz 1988).

O fruto é comestível e medicinal, sendo o caqui imaturo adstringente e o maduro laxativo (Balbach 1957).

A composição química de $100 \mathrm{~g}$ de caqui apresentou: $65,80 \mathrm{~g}$ de água, $31,60 \mathrm{~g}$ de hidrato de carbono, 0,70 $\mathrm{g}$ de proteínas, 0,70 $\mathrm{g}$ de gorduras, $1,20 \mathrm{~g}$ de sais, $2750 \mathrm{UI}$ de vitamina A, 50,00 mcg de vitamina B1 (Tiamina), 45,00 mcg de Vitamina B2 (Riboflavina) e 17,10 mg de vitamina C (Ácido Ascórbico). (Balbach 1957).

Figura 7: Época de floração e frutificação das espécies de Diospyros, no estado do Rio de Janeiro. 0 - Floração; X - Frutificação

\begin{tabular}{lccc}
\hline Meses $\backslash$ Espécies & D.ebenaster & D.incostans & D.janeirensis \\
\hline Janeiro & & $\mathrm{X}$ & $0 \mathrm{X}$ \\
Fevereiro & $\mathrm{X}$ & $0 \mathrm{X}$ & $\mathrm{X}$ \\
Março & $\mathrm{X}$ & $\mathrm{X}$ & $\mathrm{X}$ \\
Abril & $\mathrm{X}$ & $\mathrm{X}$ & \\
Maio & $\mathrm{X}$ & & \\
Junho & & $\mathrm{X}$ & \\
Julho & & $\mathrm{X}$ & \\
Agosto & & 0 & 0 \\
Setembro & & 0 & 0 \\
Outubro & $\mathrm{XX}$ & & \\
Novembro & & & \\
Dezembro & & & \\
& & & \\
\hline
\end{tabular}




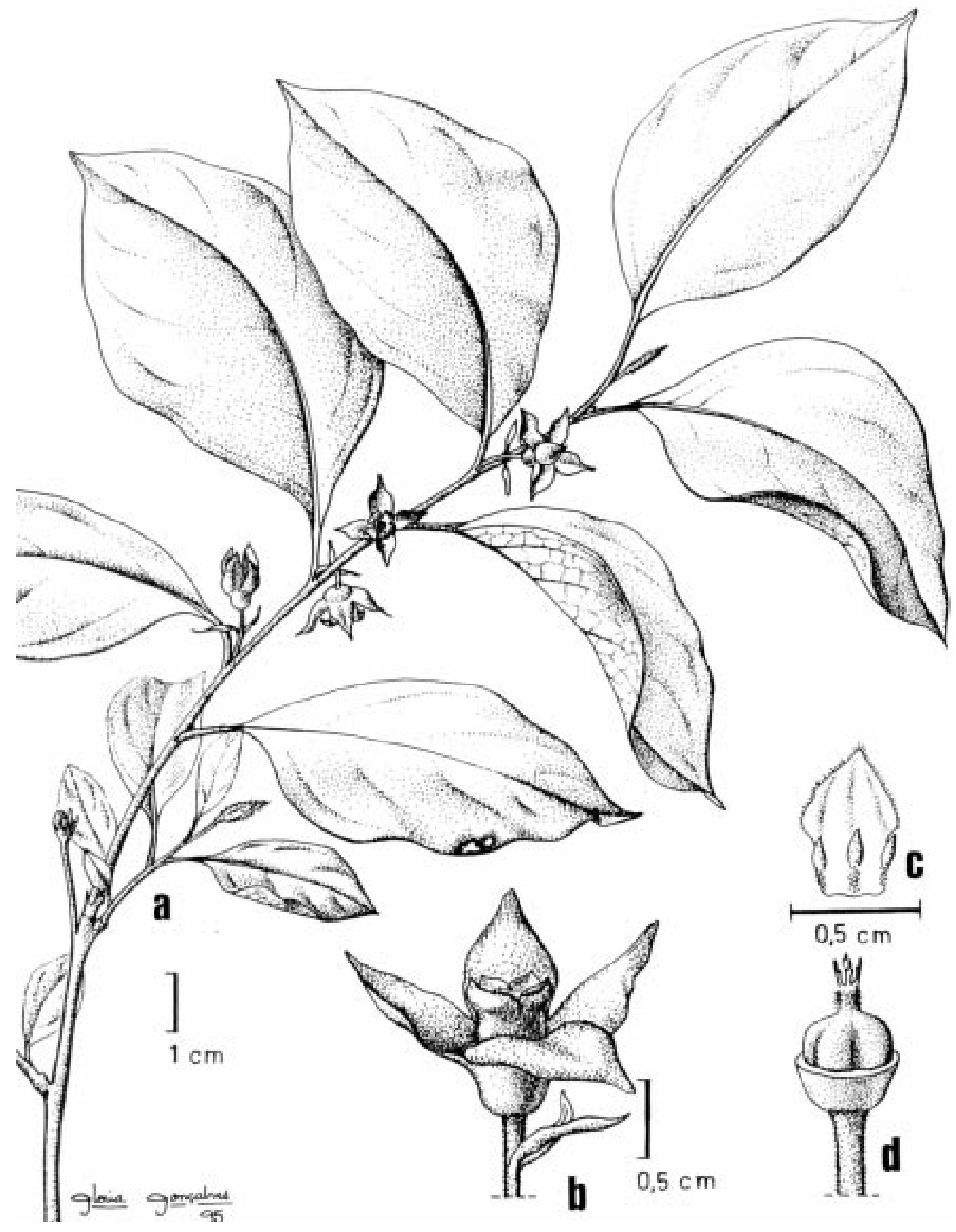

Figura 8: D.kaki (A. Duarte s/n - R), a)Inflorescência estaminada, b)Flor estaminada, c)Androceu, d)Gineceu. 
Testes para dosagem de cálcio resultaram que este fruto é pobre em cálcio, pois atividades antimicrobianas, os testes desta espécie foram negativos para vários tipos de bactérias, fungos, protozoários e vírus (Nickell 1959).

Árvore com copa arredondada; ramos cilíndricos, glabros com lenticelas; gema glabra de $0,3 \mathrm{~cm}$ de compr.. Folhas com pecíolo canaliculado de 1,0-1,5 cm de compr., lâmina ovada raro elíptica de 9,0-12,0 cm de compr. X 4,5-9,5 cm de larg., cartácea, discolor, face adaxial com pêlos esparsos nas nervuras, e face abaxial com pêlos esparsos na lâmina e adensamento de pêlos nas nervuras, base truncada ou curtamente-atenuada, ápice agudo. Flores diclinas. Flores estaminadas tetrâmeras, organizadas em inflorescências pêndulas; cálice campanulado; corola tubulosa; 10-15 estames, antera basifixa, linear. Flores pistiladas tetrâmeras; cálice campanulado; corola tubulosa; ovário com 6 lóculos e 6 óvulos, 3 regiões estigmáticas. Fruto globoso, carnoso; sementes de 1-8; embrião reto.

\section{MATERIAL EXAMINADO}

Rio de Janeiro: Município do Rio de Janeiro, Horto do Museu Nacional, cultivada, A. Duarte s/no (fl), 14.09.1971 (R); ibidem, Av. Edson Passos, curvas das águas férreas, Alto da Boa Vista, cultivada, C. A. L. Oliveira $\mathrm{n}^{\circ}$ 35 et al (fr.), 27.03.1984 (GUA); Município de Valença, Vila de Pentagna, perto do Rio Bonito, cultivada (fr.), 01.11.1967 (GUA).

\section{DISCUSSÃO E CONCLUSÕES}

A criação do gênero Embryopteris por Gaertner (1788), não era pertinente, pois analisando a figura que consta em sua obra, foi possível observar que o fruto é característico de Diospyros, apresentando cálice persistente e lobado. É um fruto bacóide do tipo campomanesoídeo, globoso, com semente de endosperma ruminado e embrião com cotilédones foliáceos. A figura só não permite observar a rafe dorsal que é muito característica e foi citada pela primeira vez em Corner (1976).

A justificativa utilizada por Rafinesque (1838) para criação de Mabola e Persimon, é considerada irrelevante visto que estudos do gênero mostraram que existem espécies com um número de estames muito acima daquele citado pelo autor, como é o caso de $D$. janeirensis.

Apesar de conter bastante detalhamento, a obra de De Candolle (1844) não apresentou ilustrações de nenhuma das espécies, o que facilitaria muito o trabalho de identificação.

Miquel (1856), ao estudar as espécies brasileiras, fez descrições incompletas e elaborou uma chave analítica de gênero baseada somente nos verticilos protetores. Cavalcante $(1962,1963)$ também trabalhou com as espécies do Brasil, fez descrições, muitas delas incompletas, devido a falta de material coletado. No entanto, elaborou uma chave analítica somente para as espécies ocorrentes na Amazônia. Angely (1917) citou as espécies ocorrentes no estado de São Paulo. Harley \& Mayo (1980) listaram as espécies ocorrentes na Bahia. Reitz (1988) descreveu e elaborou uma chave para as espécies ocorrentes no estado de Santa Catarina; e neste trabalho foram feitas descrições e chave analítica para as espécies ocorrentes no estado do Rio de Janeiro. Sendo assim, ainda se faz necessário um estudo mais aprofundado das espécies brasileiras, para complementação de suas descrições e posterior elaboração de uma chave analítica.

Com o estudo das espécies do Rio de Janeiro foi possível perceber que as folhas apresentam formas variáveis, o que facilita a sua identificação, mesmo quando encontradas estéreis em seus habitats. O estudo da organização da rede de nervuras baseado em Strittmater (1973) e Hickey (1973) ampliaram o conhecimento neste assunto, pois ainda não havia sido feito, para estas espécies, nenhum trabalho anterior. Este trabalho pode vir a subsidiar pesquisas na área da paleobotânica e, como demonstraram Carr et al (1986) na 
sistemática, facilitando identificações a nível genérico.

A inflorescência de Diospyros, foi tratada como sendo pauciflora, axilar, às vezes reduzida a uma flor (De Candolle 1844, Miquel 1856, Bentham \& Hooker 1873, Gürke 1890, Cavalcante 1962, Engler 1964, Cronquist 1981). O estudo das inflorescências baseado em Troll (1969) apontou que estas deveriam ser consideradas do tipo botrióide, resultantes da redução de um tirsóide.

Nas descrições originais das espécies estudadas, o fruto, foi uma estrutura cuja morfologia foi pouco explorada ou em alguns casos não foi observada devido a falta de material. Dos frutos estudados, somente para $D$. inconstans. havia um tratamento mais detalhado em Reitz (1988), e todas as estruturas encontravam-se desenhadas. Nos trabalhos de Jacquin (1760, 1763), De Candolle (1844), Grisebach (1864) e Burkart (1979) a espécie foi descrita, porém sem detalhamento desta estrutura. O fruto de D. janeirensis foi descrito por Sandwith (1949) a partir de um único exemplar, não havendo detalhamento das estruturas, e também das ilustrações. Posteriormente, foi tratado por Cavalcante (1963), que nada acrescentou. D. ebenaster nos trabalhos de Retz (1781, 1789 apud Howard, 1961) e Howard (1961), Howard e Norlindh (1962) não apresentava detalhamento das estruturas, nem ilustrações, sendo que em Miquel (1856) o fruto não foi considerado.

Este trabalho vem suprimir as lacunas deixadas ao longo do tempo, apresentando descrições detalhadas das 3 espécies, bem como ilustrações de todas as estruturas dos frutos.

A pesquisa apontou que a espécie $D$. ebenaster encontra-se pouco representada no Estado do Rio de Janeiro. Do indivíduo encontrado em Paraty, com amostras coletadas por L. C. Giordano, foi feito um acompanhamento, que delimitou a época de floração e frutificação da espécie.

Jacquin (1763) descreveu D. inconstans como sendo uma espécie hermafrodita, que possuía flores férteis e estéreis. A estampa apresentada no trabalho pouco auxilia no processo de identificação. Observando materiais coletados desta espécie foi possível perceber que as flores ditas férteis são as pistiladas que possuem estaminódios, e as estéreis são as estaminadas com os pistilóides. D. inconstans foi tratada anteriormente por Jacq $(1760,1763)$, como hermafrodita fértil e hermafrodita estéril. Estudos posteriores apresentados por De Candolle (1844), Grisebach (1864) e Reitz (1978, 1983, 1988) já apontavam a espécie como diclina, de flores estaminadas e pistiladas. Neste trabalho estas estruturas puderam ser observadas detalhadamente, descritas e ilustradas, o que em parte, não ocorreu em alguns dos trabalhos anteriores.

D. janeirensis em sua descrição original (Sandwith, 1949), não apresentava boas informações sobre o fruto, devido a falta de material disponível. No presente trabalho esta questão foi resolvida. Também foi apresentada pela primeira vez ilustração da espécie mostrando aspectos do ramo, flor estaminada e pistilada, fruto, semente e embrião. Devido a sua distribuição geográfica restrita, provavelmente trata-se de uma espécie endêmica do estado do Rio de Janeiro.

D. inconstans e D. janeirensis ocorrem tanto em áreas litorâneas, nas restingas e matas, como no interior, atingindo as matas das regiões serranas; e $D$. ebenaster aparece apenas em áreas de mata litorânea.

D. inconstans apresenta um grande número de material coletado depositado em herbários, quando comparado com $D$. janeirensis e D. ebenaster.

Levando-se em consideração que no estado do Rio de Janeiro existem 81 municípios e, analisando o material coletado foi possível perceber que $D$. inconstans encontra-se distribuído em 8 Municípios: Cabo Frio, Casimiro de Abreu, Macaé, Maricá, Saquarema, São João da Barra, São Pedro da Aldeia e Teresópolis. D. janeirensis com distribuição mais restrita encontra-se em 4 municípios: Macaé, Maricá, Rio de Janeiro e 
Saquarema. D. ebenaster distribui-se em 3 municípios: Angra dos Reis, Paraty e Rio de Janeiro.

O melhor período para ir ao campo e encontrar espécies em floração é entre os meses de outubro a janeiro; e para encontrar espécies em frutificação, entre os meses de janeiro a setembro (Fig. 7).

A espécie D. kaki foi tratada separadamente, pois encontra-se cultivada em extensas áreas do estado.

\section{ÍNDICE DOS COLETORES, SEUS NÚMEROS E ESPÉCIES CORRESPONDENTES}

ALFONSE - $\mathrm{s} / \mathrm{n}^{\circ}$ (D. inconstans).

ALMEIDA, C. - $\mathrm{s} / \mathrm{n}^{\circ}$ (D. janeirensis).

ARAÚJO, D. S. D. - 6123, 6687 (D. ebenaster); 5387, 6655, 7508, 8453, 8659, 8732, 8831, 8984, 9298, 9316, 10059, 10184 (D. inconstans); 5931, 6995, 7404, 9092 (D. janeirensis).

CARAUTA, J. P. P. - 473 (D. kaki).

DUARTE, AP. - 328 (D. janeirensis); s/n (D. kaki).

DUCKE, A. - $\mathrm{s} / \mathrm{n}^{\circ}$ (D. ebenaster).

FARIAS, D. S. - 311 (D. ebenaster).

FARNEY, C. - 1139, 2273, 2781 (D. incontans); 3141 (D. janeirensis).

FERNANDES, H. Q. B. - 926 (D. ebenaster).

GIORDANO, L. C. - 1648, s/ ${ }^{\circ}, 1822,2091$ (D. ebenaster).

KUHLMAN, J. G. - s/n ${ }^{\circ}$ (D. janeirensis).

LOPES, R. C. - 69, 70, 71, 72 (D. inconstans).

MARQUETE, R. - 967, 1610 (D. ebenaster).

OLIVEIRA, A. L. - 35 (D. kaki).

PEDROSA, D. S. - 1118 (D. ebenaster).

REIS, R. - 128 (D. ebenaster).

SILVA, J. G. - $\mathrm{s} / \mathrm{n}^{\circ}$ (D. inconstans).

TATO, S. - $\mathrm{s} / \mathrm{n}^{\mathrm{o}}$ (D. inconstans).

\section{AGRADECIMENTOS}

À Dra. Graziela Maciel Barroso por sua orientação neste trabalho. A UFRJ/Museu Nacional pelo apoio Institucional. Aos Curadores dos herbários consultados. Á
Coordenação de Aperfeiçoamento de Ensino Superior - Capes, pela bolsa concedida. A todos que direta ou indiretamente, ajudaram na realização deste trabalho.

\section{REFERÊNCIA BIBLIOGRÁFICA}

Angely, J. 1917 - Flora Analítica e fitogeográfica do Estado de São Paulo, São Paulo, Ed. Phyton, 4: $208 \mathrm{p}$.

Aublet, J. B. C. 1775 - Paralea Fusée (Ebenaceae). Hist. Pl. Guiane 1: 576. t. 231.

Balbach, A. 1957 - As Frutas na Medicina Doméstica, São Paulo, EDEL, 376 p.

Barbério, J. C. \& Muniz, A. M. R. 1967. Determinação do cálcio em frutas do Brasil. Utilização do BIS (2- Hidroxianil) glioxal, Rev. Fac. Farm. Bioquim. São Paulo 5(1): 197-204.

Barroso, G. M. 1978 - Sistemática de Angiospermas do Brasil, São Paulo, LTC/ EDUSP. v1. 255 p.

Barroso, G. M.; Peixoto, A. L.; Lima, M. P. M \& Ichaso, C. L. F. 1999. Morfologia de Frutos e Sementes.

Bentam, G. \& Hooker, J. D. 1873 - Ebenaceae. In: Genera Plantarum, Londini, v.2. p. 662667.

Brummit, R. K. \& Powell, C. E. 1992. Authors of Plant Names, Royal Botanical Garden. $325 \mathrm{p}$.

Burkart. 1979. Ebenaceae. Flora Il. Entre Rios 5: 27-31. fig. 8-9.

Carr, D. J.; Carr, S. G. M. \& Lenz, J. R. 1986. Leaf Venation in Eucalyptus and Other Genera of Myrtaceae: Implications for Sytems of Classification of Venation, Aust. J. Bot. 34: 53-62.

Cavalcante, P. B. 1962. Contribuição ao conhecimento do gênero Diospyros Delach. (Ebenaceae) na Amazônia, Bol. Mus.Paraense Emílio Goeldi: Bot. 20: 153.

Cavalcante, P. B. 1963. Nova contribuição ao conhecimento do gênero Diospyros Dalech. (Ebenaceae) no Brasil, Bol. Mus. Paraense Emílio Goeldi: Bot. 21: 1-15, 
est.

Corner, E. J. H. 1976. The Seeds of Dicotyledons, New York, Cambridge University Press. 311 p.

Cronquist, A. 1981. An Integrated System of Classification of Flowering Plants, New York, Columbia University Press. 519 p.

De Candolle, A. 1844. Prodromus Systemati Naturalis Regni Vegetabilis, Parisis 1(8): 209-243, 673.

Engler, A. 1964. Ebenaceae. In: A. Engler. Syllabus Der Planzenfamilien. Gebrüder Borntraeger, Berlin. p. 399-400.

Gaertner, J. 1788. De Fructibus et Seminibus Plantarum, Stutgardiae Typis Academiae Carolinae 145-146. tab. 29.

Grisebach, H. A. 1864. Ebenaceae. Fl. Brit. West. Indian Islands 6(3): 404.

Gürke, M. 1891. Ebenaceae. In: A. Engler \& K. Prantl.(eds.) Die Natürlichen Pflanzenfamilien. 4(1): 153-165.

Harley, R. M. \& Mayo, S. J. 1980 . Towards a checklist of the Flora da Bahia, Royal Botanic Gardens, Kew, Richmond, Surrey, England, p. 71-72.

Hickey, L. J. 1973. Classification of the Architecture of Dicotyledons leaves, Amer. J. Bot., 60(1): 17-33.

Howard, R. A. 1961. The Correct Name for "Diospyros ebenaster", Journal of the Arnold Arboretum 42: 430-436.

Howard, R. A. \& Norlindh, T. 1962. The Typification of Diospyros ebenum and Diospyros ebenaster, Journal of the Arnold Arboretum 43: 94-107.

Irmão Augusto. 1946. Ebenaceae. In: Flora do Rio Grande do Sul, Oficinas Gráficas da Imprensa Oficial, Porto Alegre, p. 55-58.

Jacquin, N. J. 1760. Ebenaceae. Enum. Syst. Plant. Insul. Caribaeis 34.

Jacquin, N. J. 1763. Ebenaceae. Select. Stirp. American. Hist., Oficina Krausiana, 276, tab.174, fig.67

Lawrence, G. H. M.; Buchhein, A. F. G. ; Daniels, G. S. \& Dolezal, H. 1968. Botanico - Periodico - Huntianum, Hunt Botanical Library, Pittsburgh, Pa. 1063p.
Linnaeus, C. 1754. Ebenaceae. In: Genera Plantarum..., Wien, Fr. Beck, 6: 42474251.

Miquel, F. A. G. 1856. Ebenaceae. Symplocaceae, Sapotaceae, In: Mart. Flora Brasiliensis 7: 1-117, tab. 1-47.

Nickell, L. G. 1959. Antimicrobial Activity of Vascular Plants. Economic Botany 13(4): 281-318.

Pio Corrêa, M. 1984. Dicionário das plantas úteis do Brasil e das exóticas cultivadas, Rio de Janeiro. Gráfica brasiliana ed., 16: 4329p.

Rafinesque, C. S. 1838. Trões and Shrubs of North America and other parts, Sylva Telluriana, p. 10-13 e p. 169-165.

Reitz, R. 1988. Ebenáceas, I parte; Flora Ilustrada Catarinense, fasc. Eben: 1-14.

Reitz, R., Klein, R. M. \& Reis, A. 1978. Projeto Madeira de Santa Catarina. Sellowia 2830: 23

Reitz, R., Klein, R. M. \& Reis, A. 1983. Projeto Madeira do Rio Grande do Sul. Sellowia 34-35: 31.

Rizzini, C. T. 1979. Tratado de Fitogeografia do Brasil. Aspectos Sociológicos e Florísticos. Ed. Universidade de São Paulo, São Paulo, 2:374p.

Sanchotene, M. do C.C. 1985. Frutíferas Nativas Úteis à Fauna na Arborização Urbana, Porto Alegre, RS., FEPLAM, 60p.

Sandwith, N. Y. 1949. Contributions to the Flora of Tropical America: Dr. Ducke's Collections os Diospyros in Amazonian Brasil, Kew Bull. 4: 481-493.

Stafleu, F. A. 1967. Taxonomic Literature Inter - Documentation Company A. G., Zug Switzerland, $556 \mathrm{p}$.

Stearn, W. T. 1966. Botanical Latin: History, Grammar Syntax, Terminology and Vocabulary, New York, Hafner Publishing Company, $566 \mathrm{p}$.

Strittmater, C. G. D. 1973. Nueva Técnica de Diafanización. Bol. Soc. Arg. Bot., Buenos Aires 15(1): 126-129.

Troll, W. 1969. Die Infloreszenzen. Stuttgart, Gustav Fischer Verlag, 2: 630 p. 